\title{
Ascertaining patients' understandings of their condition: a conversation analysis of contradictory norms in cancer specialist consultations
}

\author{
Kevin Dew $\mathbb{C}^{\mathrm{a}}$, Josh Barton ${ }^{\mathrm{a}}$, Jeannine Stairmand ${ }^{\mathrm{b}}$, Diana Sarfati ${ }^{\mathrm{b}}$ and Louise Signal ${ }^{\mathrm{b}}$ \\ ${ }^{a}$ School of Social and Cultural Studies, Victoria University of Wellington, Wellington, New Zealand; ${ }^{b}$ Cancer \\ and Chronic Conditions (C3) Research Group, University of Otago, Wellington, New Zealand
}

\begin{abstract}
Patient-centred care requires patients to be active participants in decision-making in consultations. Decision-making participation requires patients to understand their condition and to be able to convey their health literacy to medical specialists they encounter. Based on conversation analysis of 18 audio-recorded consultations between cancer patients and a range of cancer care specialists, this article analyses the ways cancer specialists attempt to ascertain their patient's understanding of their disease. Cancer specialists routinely enquire about their patient's understanding. In doing so, they phrase enquiries in different ways, resulting in different patient responses. How questions are phrased can require patients to deal with contradictory norms in the consultation, such as the patient being competent but not assuming medical expertise, and potentially hinder patient participation. Alternatively, questions can allow patients to draw on their own experience and so facilitate greater patient involvement. Questions aimed directly at the patient's medical understanding result in minimal or negative responses. In contrast, questions directed at what the patient has been told or has experienced, elicit longer and more in-depth responses from the patient. This analysis illuminates the co-construction of cancer specialist consultations and suggests simple ways in which patient involvement in the consultation can be facilitated.
\end{abstract}

\section{ARTICLE HISTORY}

Received 11 December 2018

Accepted 16 June 2019

\section{KEYWORDS}

Cancer care; doctor-patient interaction; observation study; interactional norms

\section{Introduction}

People are confronted with contradictory norms when interacting, or considering interacting, with the healthcare system (Ziebland, Rasmussen, MacArtney, Hajdarevic, \& Andersen, 2019). In this paper we consider contradictory norms inside the cancer healthcare consultation and suggest that an awareness of these norms has the potential to foster less problematic interactions in the difficult circumstances of these consultations. We focus on the norms that come into play when clinicians attempt to ascertain what patients know about their condition. These norms include patients being competent but not making claims of medical expertise or telling someone something they already know. The way health professionals phrase questions greatly impacts on the patients' response

CONTACT Kevin Dew $\otimes$ Kevin.Dew@vuw.ac.nz

(๑) 2019 Informa UK Limited, trading as Taylor \& Francis Group 
(Leydon et al., 2018). If patients feel unable to respond because of how questions are phrased, their opportunities to engage in the consultation and in decision-making are reduced, working against the ideals of patient-centred care and patient empowerment.

In order to tailor their information, health professionals need to let patients take the initiative early in the consultation (Heritage \& Robinson, 2006) and also ascertain patients' understandings of their condition. In routine acute consultations, patients are given the initiative through opening questions enquiring about the patient's medical concerns (such as 'what can I do for you today') (Heritage \& Robinson, 2006). Soliciting questions also allow the patient to raise their concerns and may lower patient anxiety (Leydon et al., 2018). Such enquiries do not generally occur in consultations with specialists, such as oncologists, where the patients' concerns may have already been presented as part of the referral process, and a diagnosis given (White et al., 2014). Health professionals do, however, enquire about patients' understanding (Farrell, Kuruvilla, Eskra, Christopher, \& Brienza, 2009). However, if the goals of shared decision-making (SDM) are to be enacted then it is necessary to ensure that patients are able to participate as fully as possible in that process (Heritage \& Maynard, 2006). Research indicates a range of hindrances to SDM and patient-centred care.

Physicians and patients vary in their attitudes to concepts like patient-centred care and SDM. In a review of patient barriers and facilitators to SDM, factors identified included patient characteristics (e.g. ethnicity), patient attitudes (e.g. a 'doctor knows best' attitude) and clinician characteristics (approachable or not) (Joseph-Williams, Elwyn, \& Edwards, 2014). In order to better approximate a patient-centred model of care there is a need to attend to norms that influence patient participation, such as patients' expectations to be passive in consultations (Joseph-Williams et al., 2014), and clinician' expectations that patents are communicative and know what is going on with their health (Sointu, 2017). Even in situations where clinicians are actively engaged in programmes to enhance SDM, they use a range of rhetorical devices that act to secure agreement to a preferred decision (Robertson, Moir, Skelton, Dowell, \& Cowan, 2011) and may overtly recommend or infer preferred options in the consultation (Dew, Signal, Stairmand, Simpson, \& Sarfati, 2019). Clinicians may unwittingly undermine patient involvement in decisions about treatments, for example, by leaving patients with a sense that there is no choice in treatment options (Ziebland, Chapple, \& Evans, 2015).

Researchers who focus on the details of interaction in health encounters have strongly argued that, in order to make recommendations to improve health communication, the details of actual interaction need to be understood (Pilnick, Hindmarsh, \& Gill, 2009). The use of Conversation Analysis (CA) in detailing the medical encounter has shown the collaborative nature of these encounters and how partipcants are attentive to the talk and conduct of co-participants (Pilnick et al., 2009) Through talk and interaction participants in the consultation 'establish and maintain boundaries of expertise' (Pilnick et al., 2009, p. 789). The research outlined here draws on this approach.

Farrell et al. (2009) found that health professionals routinely overtly assess patient understandings in the consultation using 'teach-back' questions. A teach-back question is defined as '[a] question whose natural answer is the patient's own version of the information covered in the conversation' (Farrell et al., 2009, p. 129). A key issue with 'teachback' is that they are taken to be tests of a patient's understanding (Koole, 2010). Vinson, in his ethnographic study of medical education in the US, observed the use of this teach- 
back format, referred to as the 'ask-tell-ask' technique in his study. This technique was meant to avoid paternalism and designed to assess a patient's knowledge of their medical problems so that the physician can determine what might need elaboration or correction. An example is students being taught to ask patients who have tests showing they have diabetes 'Do you know what diabetes is?' (Vinson, 2016, p. 1373). In Vinson's study, students are specifically taught to test knowledge. Testing knowledge evokes those contradictory norms for patients of being a competent patient and not assuming you have medical expertise.

Answering a teach-back question requires the answering party to breach two social norms of interaction. Firstly, they are informing a knowing participant about something they are already aware of. Secondly, in the case of patients, they are also breaching the norm that speakers should not make claims to which they have less epistemic access to, that is, are less expert about (Stivers, Mondada, \& Steensig, 2011). The response and expected 'minimally complete answer' to a question are determined by both the structure of the question (Heritage \& Robinson, 2006), and by the relative epistemic access of the participants (Heritage, 2012, 2013).

In medical education, students are taught how to negotiate the contradictory norms at play between patient empowerment and the students' developing medical expertise (Vinson, 2016). To empower patients to make their own decisions runs the risk of undermining the doctor, who is trained to provide diagnoses and treatment plans. In addition to their own experiences, patients draw on previous information provided to them by specialists, or other healthcare professionals (Eggly et al., 2006; Rapley, 2008; Schnitzler et al., 2017). Students may be taught about these different domains of expertise, with patients having expertise on their own circumstances and situation and clinicians having medical expertise (Vinson, 2016). The asymmetry of consultations is unavoidable (Pilnick \& Dingwall, 2011), but the level of asymmetry in consultations can be influenced by the conversational strategies employed by health professionals (Toerien, Shaw, \& Reuber, 2013).

The research reported here aimed to identify how consultation questions can facilitate, or hinder, patient involvement in the consultation. This sociological observational study draws on tools from conversation analysis to explore the sequences following cancer specialists' questions to ascertain cancer patients' understandings or experiences of their condition. In doing so, the research identifies how question formulation can bring into play contradictory norms in the consultation, that can hinder patient involvement.

\section{Methods}

The data were collected as part of a research programme to explore the cancer care journeys of patients and investigate how aspects of healthcare delivery may lead to inequitable outcomes for Māori, the indigenous peoples of Aotearoa/New Zealand (Dew, Signal, et al., 2015; Dew, Stubbe, et al., 2015). One phase of this research is drawn on here that involved the audio recording of cancer consultations between June and October 2013, which included a treatment decision as a topic.

Approval for the study was granted by the New Zealand Central Region Ethics Committee. For this phase of the research 18 patient participants and eight specialists were recruited through clinical networks in four Aotearoa/New Zealand hospitals. Patients 
were included from a range of ages (adults $\geq 18$ years), ethnicities (Māori and New Zealand European), gender, cancer types, with and without co-morbidities, who had recently received a cancer diagnosis (or high likelihood of this in the case of lung cancer) and were about to discuss their treatment options. Patients' whānau (family) were present in most consultations and cancer nurse specialists were present in some. Specialists who agreed to participate identified possible patient participants who were contacted by the researchers and received verbal and written study information and were asked to give written consent. The participating clinicians were two radiation oncologists; four medical oncologists and two surgeons. The cancers that were discussed in the consultations were breast (5), lung (4), prostate (2), bowel (2), rectal (1), stomach (1), testicular (1), skin (1) and abdominal sarcoma (1).

The digitally recorded consultations were between 24 and $71 \mathrm{~min}$ in length. On listening to the consultations and reading the transcripts it was noticed that there were occurrences where specialists appeared to ask questions to ascertain patients' understandings, and these seemed to elicit different responses. This seemed potentially pertinent to the decision-making process so a collection of all the ascertainings in the dataset was made. Of the 18 consultations, 16 contained an explicit attempt to ascertain the patient's understanding. In these 16 consultations, the question segments were anonymised and transcribed using Jeffersonian conventions (see http://www.paultenhave.nl/TranscriptionDCA-2.htm). Each question and the subsequent conversation sequence were analysed in detail. Following analysis, we grouped ascertainings into three types, direct teachback questions, indirect teach-back questions, and questions directed at patients' experiences. In all transcripts, codes have been used. MS refers to the medical specialist, PT refers to the patient, and PS to a patient's support person.

\section{Results}

As a result of the analysis, three questions types were identified across all the consultations, direct teach-back, indirect teach-back and experience questions. In the following we consider each one separately. We did not set out to classify consultations as one type or another as, in the same consultation, different questions may be used as specialists re-formulate in response to patient talk. The focus of this analysis is on the type of question and the responses to it.

\section{Direct teach-back questions}

Direct teach-back questions are directed at the patient's understanding of their condition or treatment. This type of question occurred in 5 of 18 consultations. In all five instances it resulted in a problematic interaction with misalignments between patients and specialist, minimal, negative responses from patients, or patients redirecting the target of the question to their experiences. We interpret the interactional difficulty as arising from the contradictory norms of patients displaying competence but not making claims of medical expertise, and the interactional norm of not telling someone something they already know.

An example of the minimal response given by the patient can be seen in IV18. The patient, IV18 has had cancer for 12 years and demonstrates a degree of health literacy 
throughout the consultation. However, when asked a direct 'teach-back' question in the form of a yes-no interrogative on line 12 he responds with a minimal, and soft 'no':

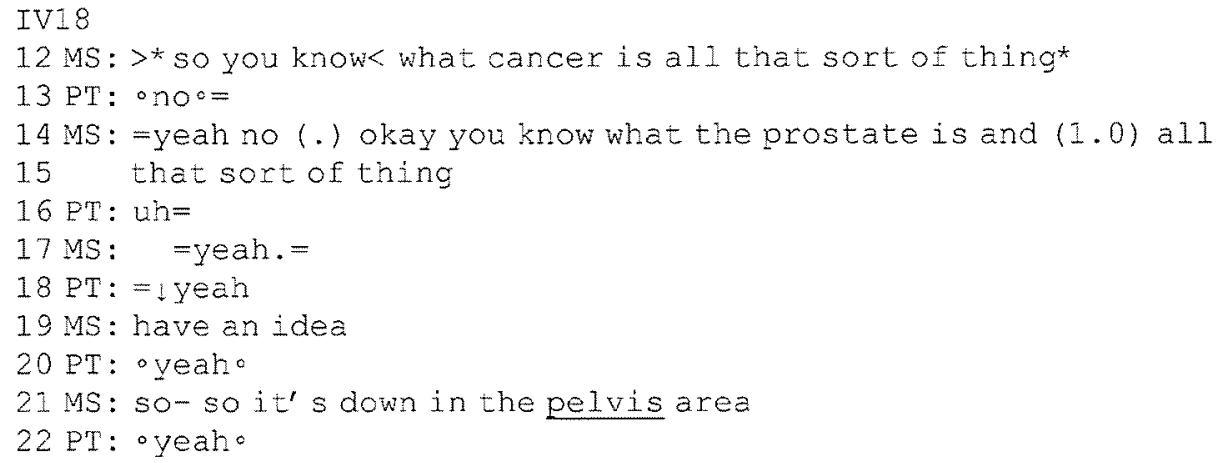

In asking the questions on lines 12 and 14, the specialist attempts to ascertain the patient's understanding of cancer. Yes-no interrogatives generally result in a minimal response that conforms with the type of interrogative (affirmative or negative) (Schegloff, 2007) and so a minimal response is expected. However, by phrasing the enquiries as direct teach-back questions, first about cancer and secondly about the prostate, we infer that the enquiry is received as something like a test of the patient's understanding of their condition from a medical perspective. The patient's responses are quiet, firstly the 'no' on line 13 in response to the direct question about whether they know what cancer is. There is a hesitant 'yeah', suggested by its lower pitch, on line 18, after being asked about his knowledge of the prostate, which followed a minimal response on line 16, and a quiet affirmative response on line 20 . The patient is establishing the boundary of expertise but not laying claim to medical knowledge.

As mentioned above, elsewhere the patient demonstrates a greater level of health literacy than this interaction would suggest. However, to answer the question the patient would have to demonstrate a high level of technical understanding. To do so would break both the norm of not providing information already known, and it would be informing an expert of that technical understanding. There is a misalignment between the specialist's attempt to ascertain the patient's understanding and the patient not breaching norms of claiming medical expertise. Given the phrasing of the question as requiring a 'yes/no' and the expertise requirements of a teach-back question, this interaction does not result in the patient offering any further information, demonstrating their understanding or raising concerns.

Teach-back questions are not always phrased as yes/no interrogatives, but even when they are less constraining the patients' response is minimal. The tendency for direct teach-back questions being treated as tests, and thus receiving minimal responses, was acknowledged by the specialist in IV13. MS provides a pre-account with 'my next question to you sounds like a quiz', which is designed to minimise the chance of IV13 hearing the question as a test.

IV13

04 MS: my next question to you sounds like a quiz but it's not meant

05 to be

$06 \mathrm{PT}:{ }^{\circ} \mathrm{mhm} \circ=$ 


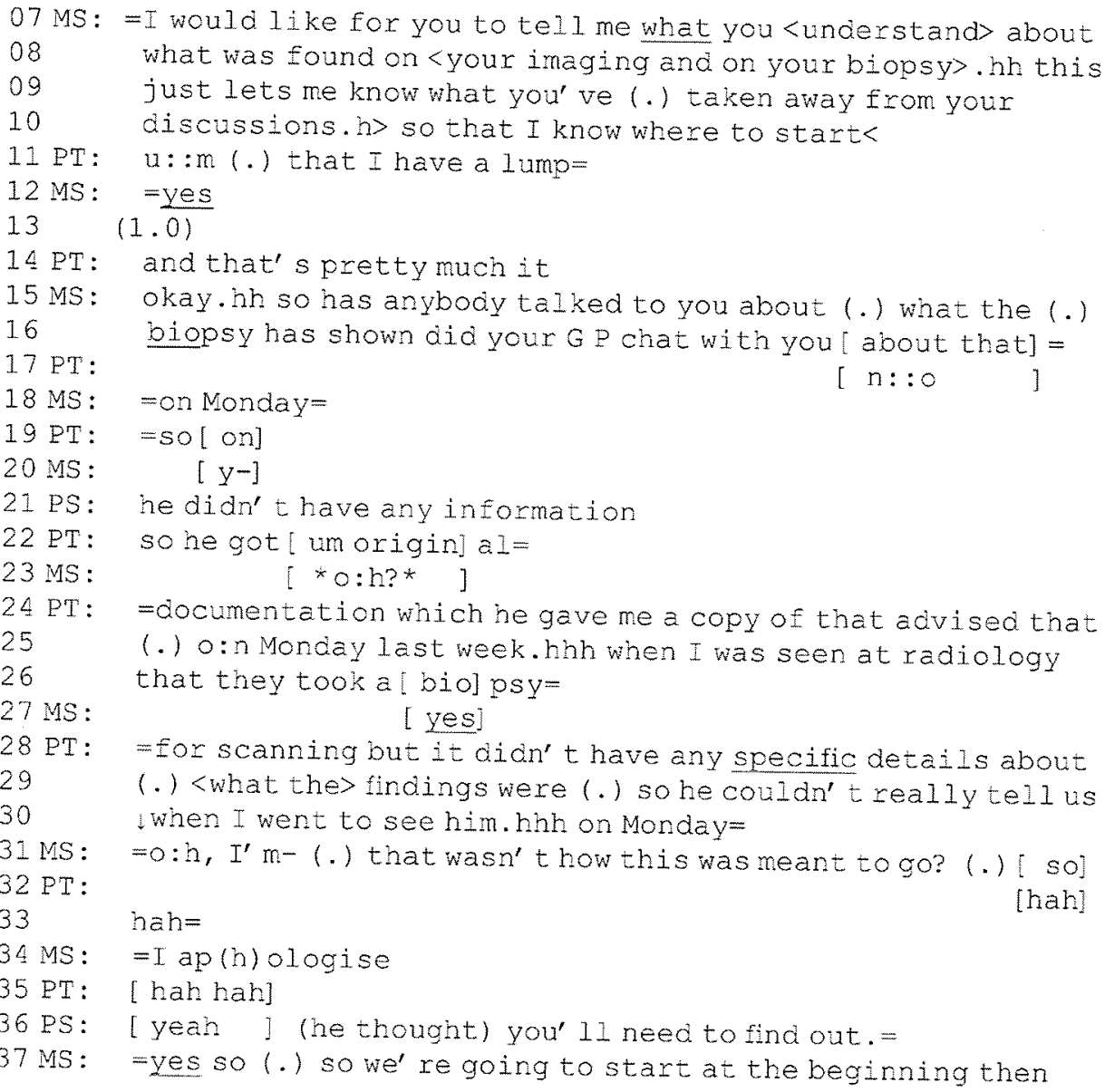

The patient initially gives a short confirmative response to the teach-back question on line 11, beginning to describe her knowledge. The pause on line 13 is likely the result of the specialist waiting for a longer response, but the patient closes their turn on line 14 . The specialist rephrases the ascertaining toward the knowledge imputed by a third party (the patient's GP) on lines 15-16, and 18. The question is no longer about the patient's understanding but what they have been told, and the patient is able to give a stronger negative response on line 17 (corroborated by the patient's support person on line 21), which they then elaborate on lines 22, 24-26, and 28-30. Whilst the patient does not provide any additional medical information, clarifying that they have not received any additional details on line 28 , they are able to provide additional information about their experiences. On line 31 the specialist acknowledges that there is a problem in that the patient does not know the outcome of the biopsy, something the specialist expected the patient to know. The specialist apologises on line 34, realising that important information has not been made available to the patient, and moves to repair this situation by starting 'at the beginning' (line 37).

Despite the health professional attempting to address the issue of teach-back questions being received as a quiz, and raising potential third parties for the patient to draw upon on lines 7-10, the patient still provided minimal information in response to the direct teachback question. The specialist was able to obtain a more sufficient response by changing the question agenda (Stivers \& Hayashi, 2010, p. 8) to one about what the patient has been told. 
IV16 demonstrates the difficulties that emerge from direct teach-back questions, but also indicates that specialists can successfully solicit a longer response, by raising the patient's interactions with a third party. In lines 13 and 14 the specialist opens by asking a direct teach-back question (what you know so far) and also solicits questions from the patient:

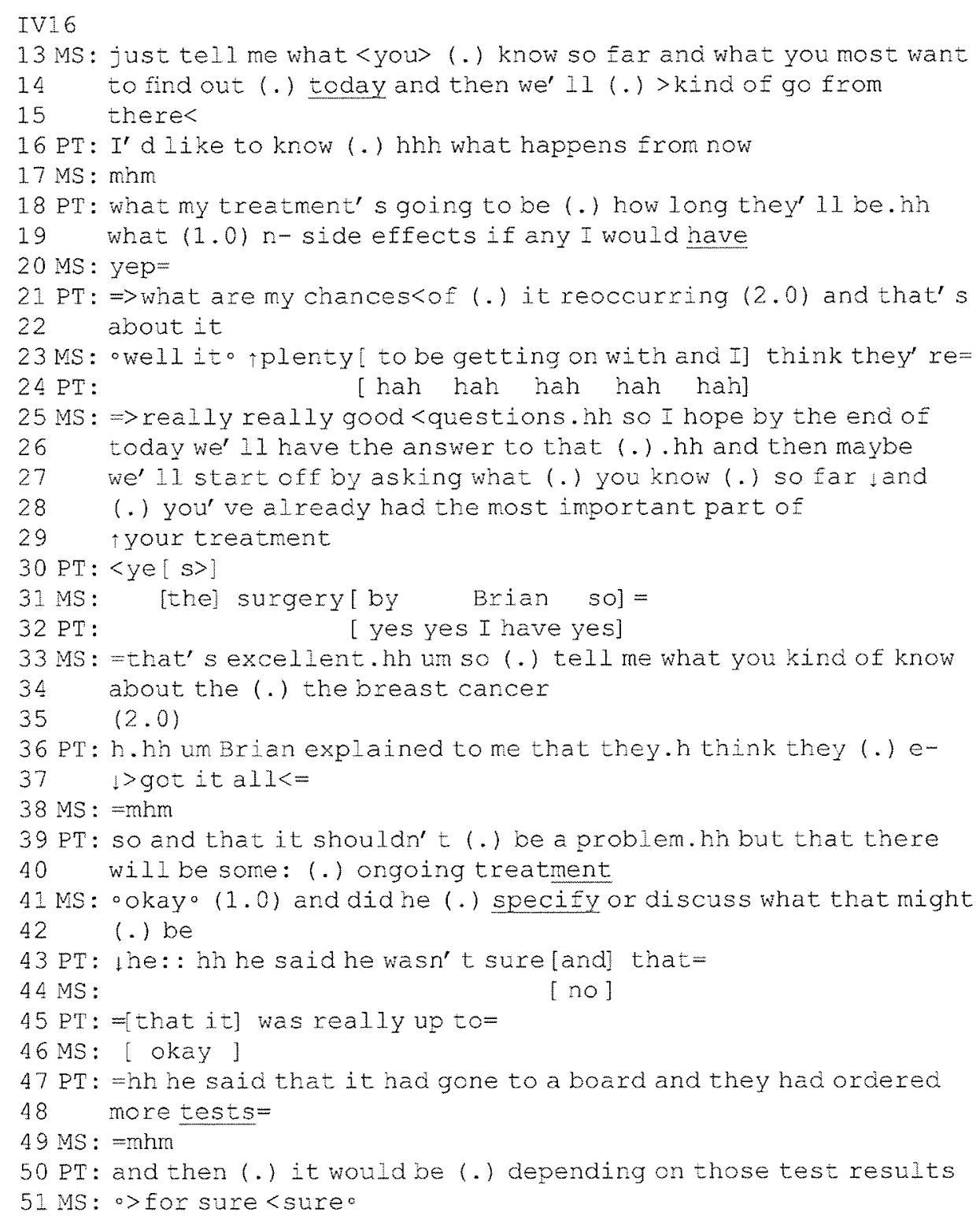

On lines $16,18,19$, and 21 the patient avoids responding to the teach-back questions and responds only to the request for questions. This leads to the long turn by the medical specialist on lines $23,25-29$ and 31 , which affirm the patient's choice of questions (really really good questions), before reiterating the teach-back question on line 27 (what you know so far). However, this is again followed by another question in a yes/ no form, and which the patient responds to. The teach-back question is restated for a third time on lines 33-34 (tell me what you kind of know about the breast cancer), this 
time unaccompanied by another question. However, in the same turn the specialist also mentions a third party, Brian, on line 36, and mentions the patient's experiences. Raising the third party provides an opportunity for the patient to reorient the question target toward what they have been told by Brian (lines $36,37,39,40,43,47,48$ ) rather than their health literacy and a test of their own expertise.

In one instance the patient was able to reorient a direct teach-back question by responding with a discussion of their experiences and so provide a longer response:

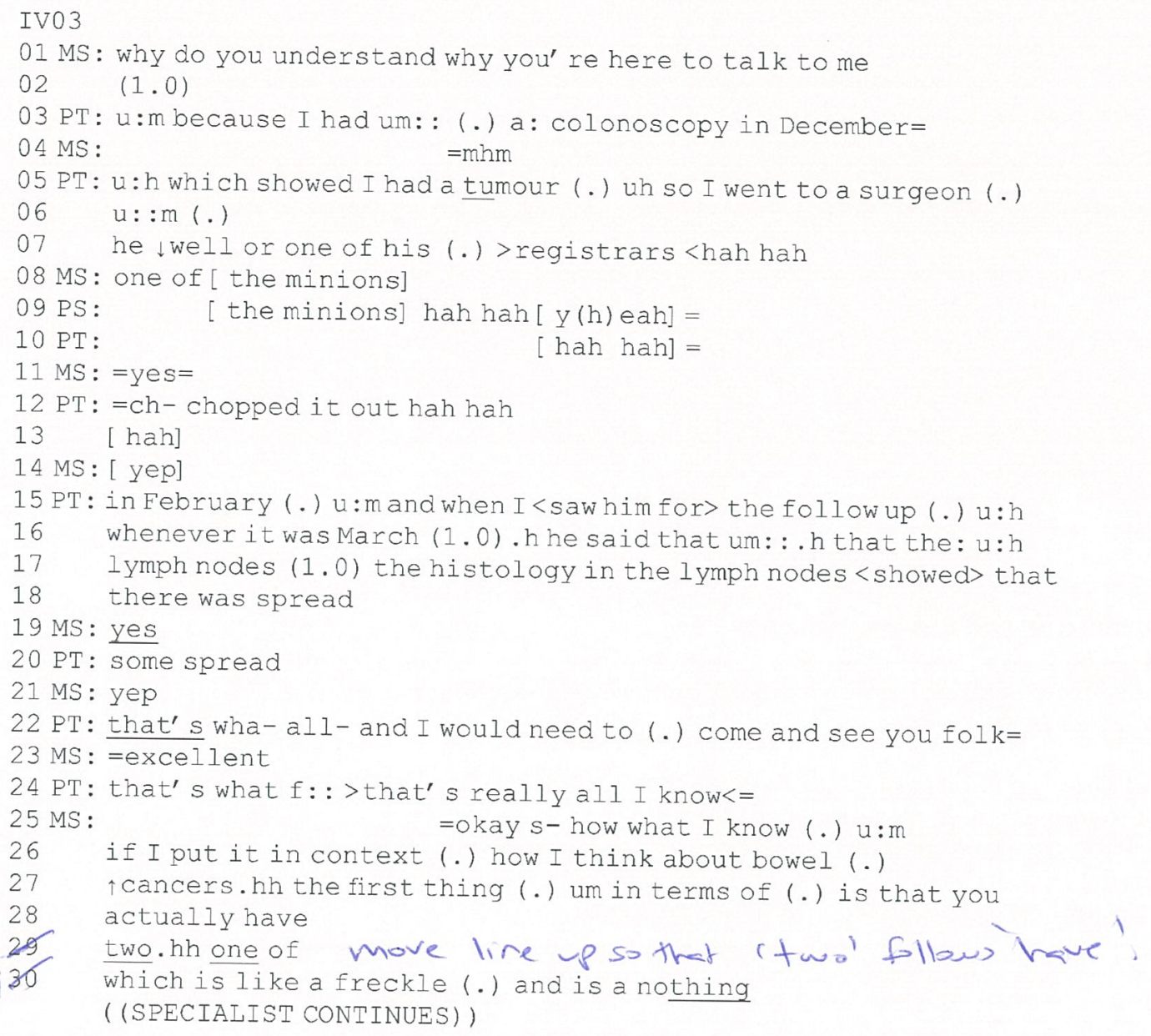

After a long pause, the patient responds to the question 'do you understand why you are here' by giving the history of their treatment, mentioning the discovery and diagnosis (lines $03,05,06,07$ ), surgery (lines $07,10,12$ ), and the identification of the spread of the cancer (lines 15-18,20). Again, the patient invokes a third party and what 'he said' (line 16). Thus, they have interpreted the question as enquiring about their medical history, as opposed to their understanding of the disease, and the technical language of histology is imputed to a third party. Evoking third parties means any possible misunderstandings can be attributed to that third party and not to the patient's competence. The specialist provides a positive assessment to the patient's response on line 22 with 'excellent', followed by a medical understanding of the patient's condition, diagnosis and 
prognosis, putting the patient's experiences and understandings from third parties in context' (line 26). This interaction indicates that, even when direct teach-back questions are successful in eliciting the patient's understanding, such questions still require work from the patient. The ambiguous targeting of the question at 'why you are here' can be interpreted by the patient as allowing them to discuss their journey, rather than demonstrating their expertise in relation to their condition.

The examples presented here highlight the difficulty that patients face in responding to a direct teach-back question. Patients either give minimal, negative responses or redirect the question to their experiences, including what they have been told. Direct teach-back questions evoke contradictory patient norms. The patient must provide technical information that the specialist already knows and demonstrate their understanding to a specialist. If their understanding is inadequate, they risk being viewed as incompetent or lacking concern. The potential contradiction can be resolved if a third party can be appealed to. The teach-back form of question also requires more work from health professionals, as the consultation with IV03 and IV16 indicates. The health professional may have to repeat and rephrase the question to receive an adequate response, or explicitly reassure the patient that the question should not be received as a test.

\section{Indirect teach-back questions}

Indirect teach-back questions are directed at the information provided by third parties, rather than patients' understandings. As IV03 and IV16 indicate, patients draw on third parties to provide a longer response to direct teach-back questions. Indirect teach-back questions more easily elicit longer responses than direct teach-back questions. They are not received as tests of the patient's medical knowledge, but instead of the patient's experiences of being told medical knowledge. When reporting what a third party has stated, patients avoid the clash over appearing competent but not claiming expertise or telling someone something they already know. There were five instances of this type of question in the dataset.

IV01 provides a good example of an indirect teach-back question that easily elicits a detailed response from the patient. This question does not explicitly evoke a particular third party, but enquires about the information provided to the patient:

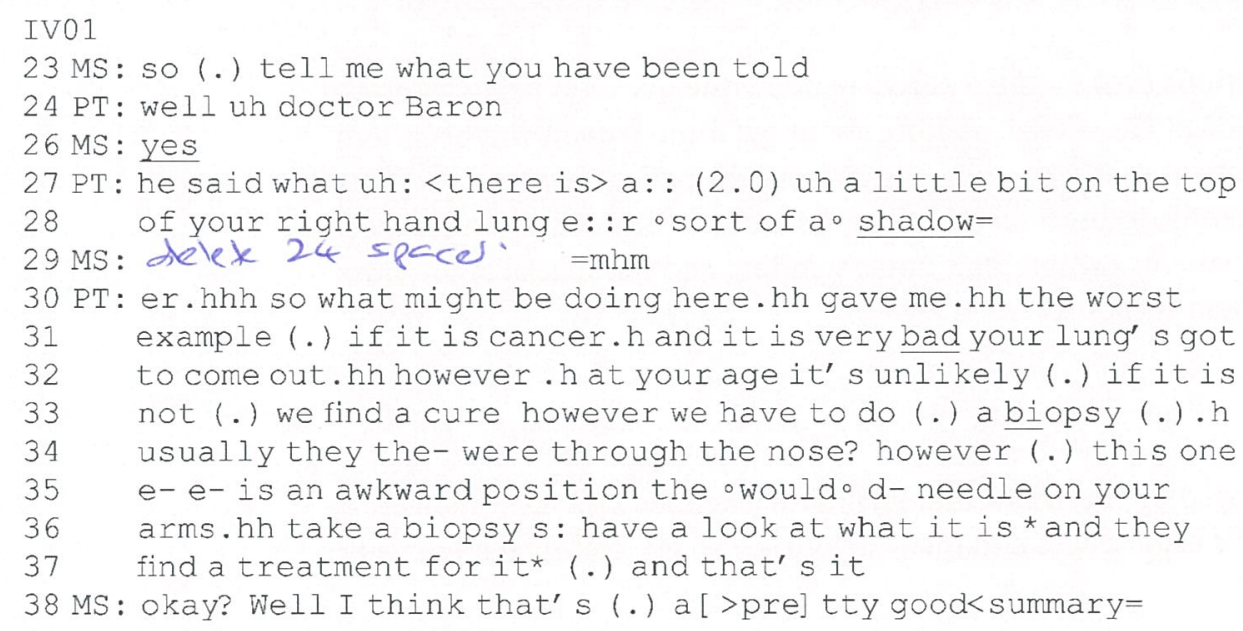


The patient begins their response to the indirect teach-back question on line 23 by evoking the name of an expert third party on line 24 (doctor Baron). This is followed by a long turn of talk conveying what they have been told by that party on lines $27-28$ and $30-38$. Their 37 response demonstrates an understanding of their condition and possible treatment options, which the specialist acknowledges and provides a positive assessment of the 38 patient response on line 39 (that's a pretty good summary).

A similar question occurred in IV09:

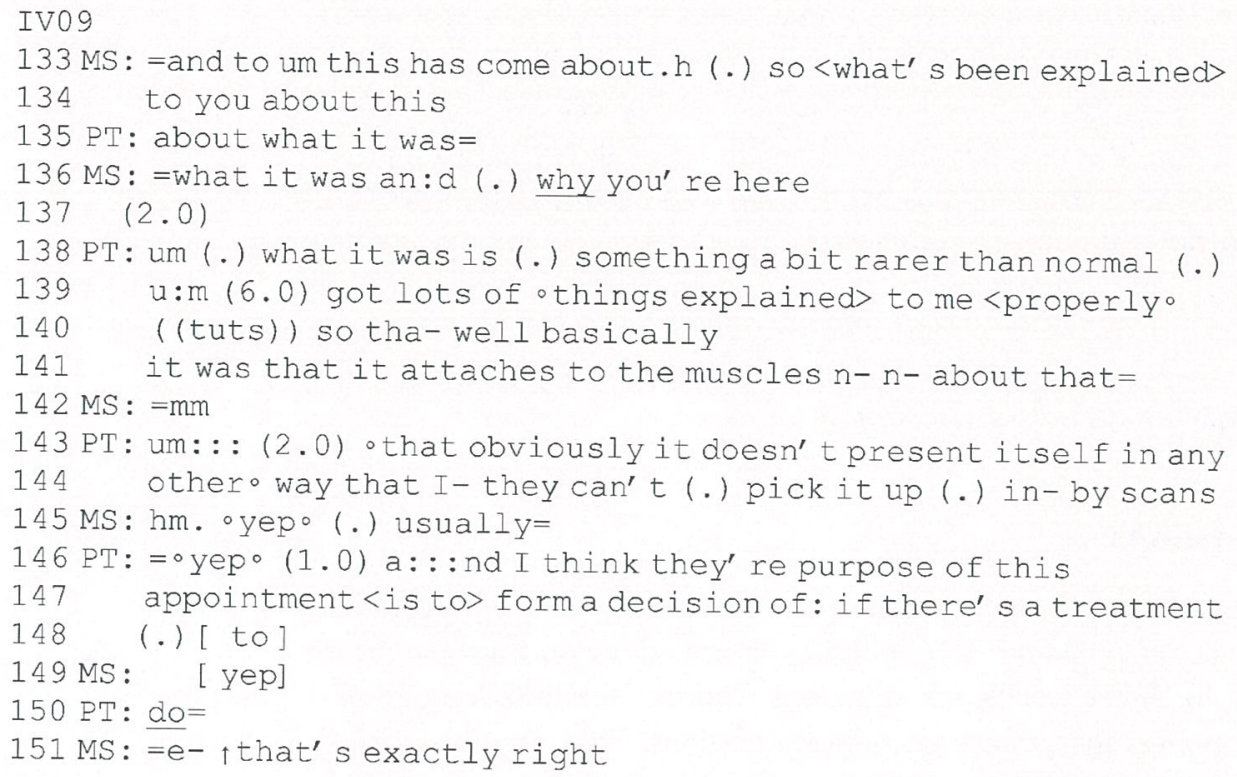

IV09 has already had surgery and prior to this segment the specialist, a radiation oncologist, has asked about the response to surgery and other general health matters. The specialist then moves on to ascertaining what IV09 understands about 'this', a euphemism for the cancer, and the purpose of this particular consultation. Again, the patient exhibits an understanding of their condition in a long response on lines 138-141 and 143-144 but does not name a particular third party, instead stating that things were explained properly. As with IV01 the specialist provides a positive assessment of the response on line 151.

Indirect teach-back questions evoke a third party, avoiding the question being received as a test of the patient's medical knowledge. Asking about what the patient has been told transfers the onus for the patient's understanding away from the patient and to a previous medical specialist. Consequently, indirect teach-back questions are more likely to result in extended responses, where patients exhibit their understanding and the specialist provides positive assessments to patient responses.

\section{Experience questions}

Another ascertaining employed by specialists that facilitates extended patient responses is to enquire about the patient's experiences and medical journey so far, of which there were six instances. For example: 
IV15

09 MS: um but before we get into that hh can you just tell me what's

10 been happening

11 (.) when did you first notice the problem

\section{IV07}

56 MS: what I would like to know a bit more about is. hh how does it all

57 come about you know what what was it you felt that led to this

58 <being> f found

Rather than requiring the patient to demonstrate their expertise, these questions are directed at the interaction between medicine and the patient's lifeworld from the perspective of the lifeworld (Mishler, 1984). Consequently, this form of question elicits long responses that are assessed positively by the specialist. Patients can provide accounts that may convey new information to the expert, and recounting one's experience does not require a display of competence to someone who is an expert.

IV12 provides an example of experience questions eliciting a detailed response, including the patients' uncertainties:

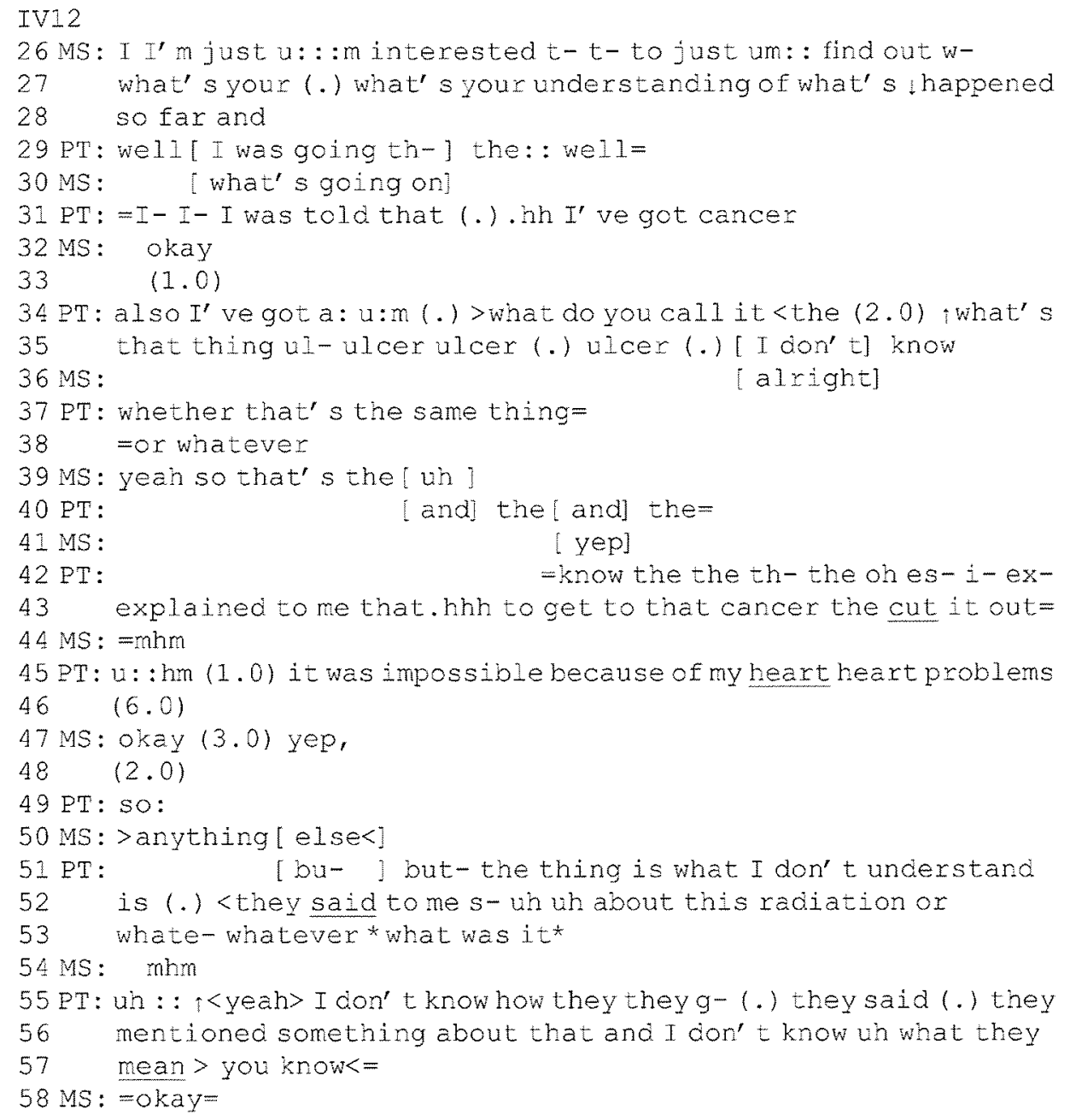




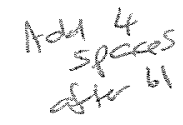

59 PT: =what they<mean $>$

$60 \mathrm{MS}$ : sure tyep (2.0) <and> fanything el se that you thought about

61 lor: (.) need to ask about

$62(1.0)$

63 PT: well (1.0) I know I' ve got cancer but there' s nothing they can

64 do about it you [ know]

65 MS: [lokay] (.) alright (.) ((tut)) tokay.hh so um

66 I'II just sort of:

67 slightly go back you' ve you ve been in and out of hospltal a

68 iltelebit haven't you=

The question on lines 26-28 asks for the patient's understanding of what has happened so far, as opposed to their understanding of their condition. The patient response on line 31 , as with responses to indirect teach-back questions, evokes a third-party expert ("well I was told'). The patient's response demonstrates a combination of their understanding, such as being aware of why surgery is not an option on lines 43 and 45 , and also allows them to highlight areas they wish to discuss further, such as ulcers (line 35) and radiotherapy (lines 51-52). The specialist was able to ascertain the patient's level of understanding and later responds accordingly with an explanation of ulcers, cancer and treatment options (not shown).

A more ambiguous case occurred in IV06 in which the specialist expresses a wish to establish where the patient is 'up to' with knowing about their investigations (lines 0810). Whilst this question is directed at the patient's understanding ('knowing'), it is also directed at the patient's experiences (their investigation):

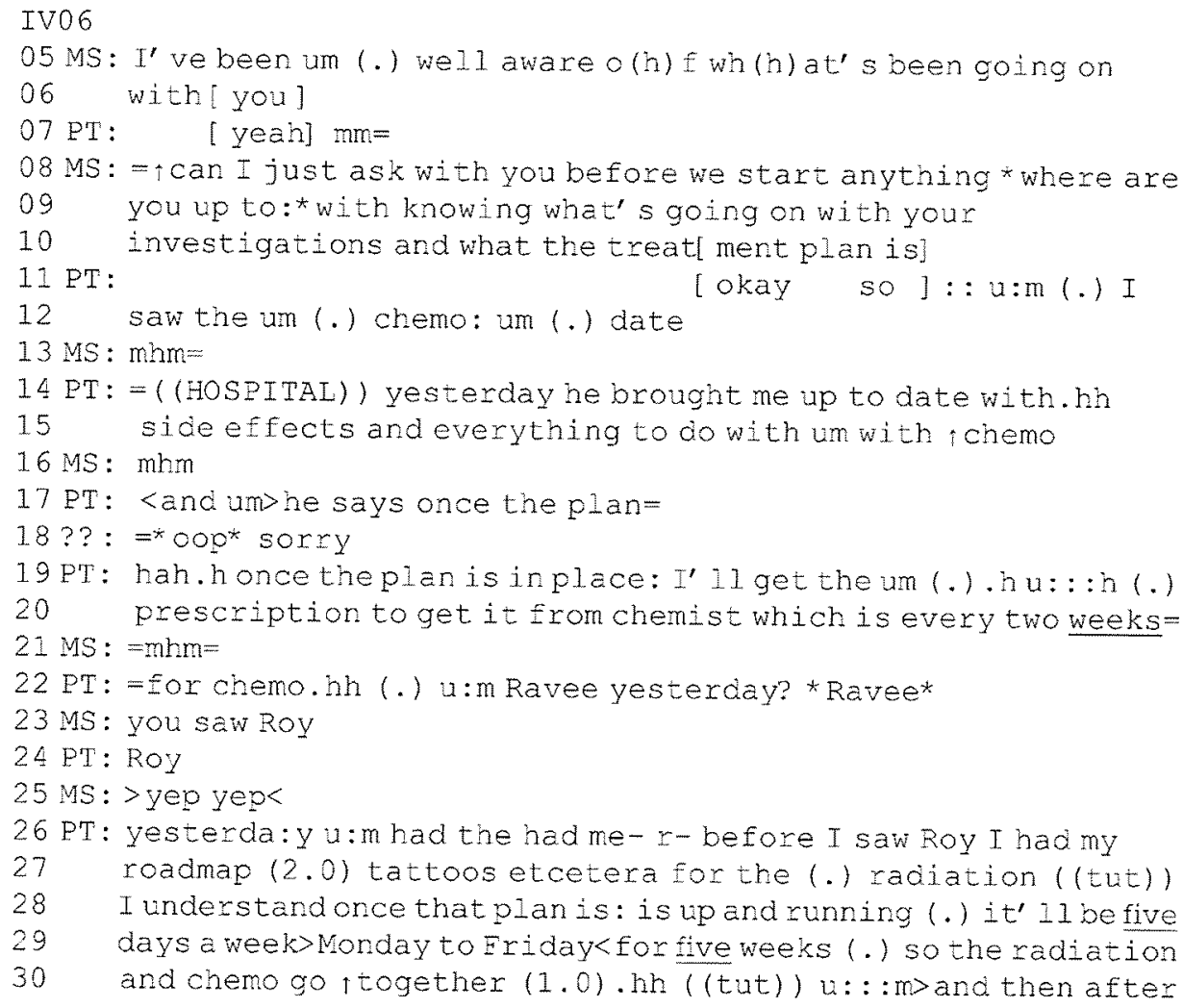


31 that<uh the radiation will still be (.) taking effect and

32 there' 11 bea (.) like a sixweek periodbefore (.) I have (.)

33 an operation

34 MS: okay.h who was it * you saw from <chemo> (.) can you remember

$35<$ who that was:

On lines 5 and 6 the specialist states that they are well aware of the patient's experience, before asking for that information again on lines 8-10. In this instance, the specialist has stated that they are a knowing recipient of the teach-back question, however the patient still provides a long response that demonstrates an understanding of their condition. The patient responds by focusing on 'what's been going on' as a set of events and is also able to demonstrate their medical knowledge (for instance being up to date with the side effects and 'everything to do with the chemo' on lines 13-14). However, whilst the patient raises medical knowledge and understanding, they do so in relation to their experiences, by discussing what they have been told by third parties (e.g. Roy). Unlike when asking a teach-back question about the patient's medical understanding, the patient can draw on their experiential knowledge. Questions directed at the patient's experiences allow the patient to respond from their own experiences and allow the patient to exhibit their understanding as they are not having to demonstrate expertise, and there is less risk of being seen as incompetent.

\section{Discussion}

For patients in this data set, 'teach-back' questions were less effective at establishing the patient's level of understanding of their condition than questions directed at either what they had been told, or what they had experienced so far. With the former, the patient is required to demonstrate their medical expertise in the presence of a co-participant who has the authority of medical expertise. Patients respond to these questions either with minimal negative responses or by changing the question agenda to one where they can talk about what they have been told. Questions directed at what patients have been told (an indirect teach-back question), or at their experiences so far, allow patients to impart their broader experiences of their medical journey, and bring in third party sources of knowledge to facilitate patient involvement in the consultation (Rapley, 2008). In facilitating a demonstration of the patient's understanding by seeking out their experiences and avoiding quizzing patients, the consultation is likely to be a more participative one, which has been shown to improve both patient and doctor satisfaction with consultations (Gattellari, Butow, \& Tattersall, 2001)

The findings reported here are relevant to different theoretical and practical domains. At a theoretical level, they inform us about the limits around patient-centred care that is an outcome of interactional social norms. At a practical level, it allows for the consideration of simple interventions that can promote patient participation; interventions that are sensitive to the interactional social norms that are invoked in this institutional setting.

When clinicians ask patients what they know about their clinical condition, patients are confronted with what we could term structural norms (Ziebland et al., 2019) and interactional norms, and these norms can be contradictory. Patients are confronted with one norm that, as a good patient, they are expected to answer the question to the best of their ability, but if they err or provide an inadequate response, they risk being viewed 
as a bad patient (Sointu, 2017). Sointu suggests that a consequence of being viewed a bad patient is that clinicians may deem you as not unworthy of extra effort. Further, she suggests that the developing norms around patient-centred care that demand patient involvement risks patients being categorised into those less committed and those more deserving (Sointu, 2017).

A structural root of these contradictory norms is the asymmetry of doctor/patient relations, which has been embedded in western medical practice since the mid-nineteenth century (Shorter, 2006). In the mid-nineteenth century, the patient was now viewed as a passive object of the clinical gaze, as opposed to an active subject in the consultation, a shift that Jewson (2009) referred to as the disappearance of the sick man from medical cosmology. Pilnick and Dingwall (2011, p. 1374) suggest that to reform doctor/patient interactions we must 'acknowledge the inescapability of medical authority and patient deference in the consultation'. For Pilnick and Dingwall, the goal of analysis is to separate out dysfunctional asymmetry from functional asymmetry. Our research contributes to this goal by showing the interactional difficulties that can occur when patients are confronted with contradictory norms, and how these interactional difficulties can be addressed.

It has been argued that patients need to be given permission to display their understandings (Joseph-Williams et al., 2014), and that permission is not well served if it is received as a test of knowledge. Tools that have been developed to promote shared decision-making focus on concerns such as active listening and deliberation (Elwyn et al., 2017), but do not explicitly deal with the issue of ascertaining patient's understanding.

A strength of this research is that through a close analysis of how specialists attempt to ascertain cancer patients' understandings of their condition we have identified the importance of question formulation in facilitating or hindering patient displays of their understanding. We have related this finding to the interactional norms that are at play in consultations and argue that attention to these norms, and the effects of question formulation, can promote more patient involvement in the consultation. The limited data set has meant that we cannot make any statements about how these consultations might vary by ethnic, cultural or social differences. Conversation analysts are aware that culture comes into play in talk and interaction (Luke \& Pavlidou, 2002). In the data presented in this paper there are, for example, Māori and New Zealand European participants. It is entirely possible that interactional norms vary across these groups and in relation to specific aspects of upbringing and education, and these may influence the interactions in this data set.

In clearly delineating the interactional norms in the cancer consultation, of patients' displaying competence but not claiming expertise and not telling experts something they already know, an important element of the co-construction of patient participation in consultations can be discerned. Health professional awareness of these norms would provide greater opportunities for patient involvement in the consultation process, and would also provide opportunities to reduce patient stress and make better use of the consultation time. Ascertaining patients' understandings of their condition, in the stressful environment of the cancer specialist consultation, by attending to interactional norms can potentially enhance patient-centred care.

\section{Disclosure statement}

No potential conflict of interest was reported by the authors. 


\section{Funding}

This work was supported by Health Research Council of New Zealand: [Grant Number 11/202].

\section{ORCID}

Kevin Dew (D) http://orcid.org/0000-0003-3159-0413

\section{References}

Dew, K., Signal, L., Davies, C., Tavite, H., Hooper, C., Safati, D., .. Cunningham, C. (2015). Dissonant roles: The experience of Māori in cancer care. Social Science \& Medicine, 138, 144-151.

Dew, K., Signal, L., Stairmand, J., Simpson, A., \& Sarfati, D. (2019). Cancer care decision-making and treatment consent: An observational study of patients' and clinicians' rights. Journal of Sociology, 55(1), 161-178. doi:10.1177/1440783318773880

Dew, K., Stubbe, M., Signal, L., Stairmand, J., Dennett, E., Koea, J., ... Holdaway, M. (2015). Cancer care decision making in multidisciplinary meetings. Qualitative Health Research, 25 (3), 397-407.

Eggly, S., Penner, L., Greene, M., Harper, F., Ruckdeschel, J., \& Albrecht, T. (2006). Information seeking during "bad news" oncology interactions: Question asking by patients and their companion. Social Science and Medicine, 63, 2974-2985.

Elwyn, G., Durand, M. A., Song, J., Aarts, J., Barr, P. J., Berger, Z., ... Van Der Weijden, T. (2017). A three-talk model for shared decision making: Multistage consultation process. Bmj, 359, j4891. doi:10.1136/bmj.j4891

Farrell, M., Kuruvilla, P., Eskra, K., Christopher, S., \& Brienza, R. (2009). A method to quantify and compare clinicians' assessments of patient understanding during counseling of standardized practices. Patient Education and Counseling, 77, 128-135.

Gattellari, M., Butow, P. N., \& Tattersall, M. H. N. (2001). Sharing decisions in cancer care. Social Science \& Medicine, 52(12), 1865-1878.

Heritage, J. (2012). Epistemics in action: Action formation and territories of knowledge. Research on Language and Social Interaction, 45(1), 1-29.

Heritage, J. (2013). Action formation and its epistemic (and other) backgrounds. Discourse Stwdies, 15(5), 551-578.

Heritage, J., \& Maynard, D. (2006). Problems and prospects in the study of physician-patient interaction: 30 years of research. Annual Review of Sociology, 32, 351-374.

Heritage, J., \& Robinson, J. (2006). The structure of patients' presenting concerns: Physicians' opening questions. Health Communication, 19(2), 89-102.

Jewson, N. D. (2009). The disappearance of the sick-man from medical cosmology, 1770-1870. International Journal of Epidemiology, 38(3), 622-633. doi:10.1093/ije/dyp180

Joseph-Williams, N., Elwyn, G., \& Edwards, A. (2014). Knowledge is not power for patients: A systematic review and thematic synthesis of patient-reported barriers and facilitators to shared decision making. Patient Education and Counseling, 94, 291-309.

Koole, T. (2010). Displays of epistemic access: Student responses to teacher explanations. Research on Language and Social Interaction, 43(2), 183-209.

Leydon, G., Stuart, B., Summers, R., Little, P., Ekberg, S., Stevenson, F., ... Moore, M. (2018). Findings from a feasibility study to improve GP elicitation of patient concerns in UK general practice consultations. Patient Education and Counseling, 101, 1394-1402. Online First.

Luke, K. K., \& Pavlidou, T. (2002). Studying telephone calls: Beginnings, developments and perspectives. In Kang Kwong Luke \& Theodossia-Soula Pavlidou (Eds.), Telephone calls unity and diversity in conversational structure across languages and cultures (pp. 3-21). Philadelphia, PA: J. Benjamins Pub.

Mishler, E. (1984). The discourse of medicine: dialtectics of medical interviews. Norwood, NJ: Ablex. 
Pilnick, A., \& Dingwall, R. (2011). On the remarkable persistence of asymmetry in doctor/patient interaction: A critical review. Social Science \& Medicine, 72(8), 1374-1382. doi:10.1016/j. socscimed.2011.02.033

Pilnick, A., Hindmarsh, J., \& Gill, V. T. (2009). Beyond 'doctor and patient': Developments in the study of healthcare interactions. Sociology of Health \& Illness, 31(6), 787-802. doi:10.1111/j.14679566.2009.01194.x

Rapley, T. (2008). Distributed decision making: The anatomy of decisions-in-action. Sociology of Health and Illness, 30(3), 429-444.

Robertson, M., Moir, J., Skelton, J., Dowell, J., \& Cowan, S. (2011). When the business of sharing treatment decisions is not the same as shared decision making: A discourse analysis of decision sharing in general practice. Health: An Interdisciplinary Journal for the Social Study of Health, Illness and Medicine, 15(1), 78-95. doi:10.1177/1363459309360788

Schegloff, E. (2007). Sequence organization in interaction: A primer in conversation analysis (Vol. 1). Cambridge: Cambridge University Press.

Schnitzler, L., Smith, S., Shepherd, H., Shaw, J., Dong, S., Carpenter, D., ... Dhillon, H. (2017). Communication during radiation therapy education sessions: The role of medical jargon and emotional support in clarifying patient confusion. Patient Education and Counseling, 100, 112-120.

Shorter, E. (2006). Primary care. In R. Porter (Ed.), The Cambridge history of medicine (pp. 103135). Cambridge: Cambridge University Press.

Sointu, E. (2017). 'Good' patient/'bad' patient: Clinical learning and the entrenching of inequality. Sociology of Health \& Illness, 39(1), 63-77. doi:10.1111/1467-9566.12487

Stivers, T., \& Hayashi, M. (2010). Transformative answers: One way to resist a question's constraints. Language in Society, 39, 1-25.

Stivers, T., Mondada, L., \& Steensig, J. (2011). Knowledge, morality and affiliation in social interaction. In T. Stivers, L. Mondada, \& J. Steensig (Eds.), The morality of knowledge in conversation (pp. 3-26). Cambridge: Cambridge University Press.

Toerien, M., Shaw, R., \& Reuber, M. (2013). Initiating decision-making in neurology consultations: 'recommending' versus 'option-listing' and the implication for medical authority. Sociology of Health and Illness, 35(6), 873-890.

Vinson, A. H. (2016). 'Constrained collaboration': Patient empowerment discourse as resource for countervailing power. Sociology of Health \& Illness, 38(8), 1364-1378. doi:10.1111/1467-9566.12480

White, S. J., Stubbe, M., Macdonald, L., Dowell, A., Dew, K., \& Gardner, R. (2014). Framing the consultation: The role of the referral in surgeon-patient consultations. Health Communication, 29(1), 74-80.

Ziebland, S., Chapple, A., \& Evans, J. (2015). Barriers to shared decisions in the most serious of cancers: A qualitative study of patients with pancreatic cancer treated in the UK. Health Expectations, 18(6), 3302-3312. doi:10.1111/hex.12319

Ziebland, S., Rasmussen, B., MacArtney, J., Hajdarevic, S., \& Andersen, R. S. (2019). How wide is the Goldilocks Zone in your health system?. Journal of Health Services Research \& Policy, 24(1), 52-56. 